\title{
A new application of pelvis area data as culling tool to aid in the management of dystocia in heifers 1
}

\author{
D. E. Holm, ${ }^{* 2}$ E. C. Webb, $\uparrow$ and P. N. Thompson* \\ *Department of Production Animal Studies, Faculty of Veterinary Science, \\ University of Pretoria, Private Bag X04, Onderstepoort, 0110, South Africa; and $\dagger$ Department of Animal \\ and Wildlife Sciences, Faculty of Natural and Agricultural Sciences, University of Pretoria, Pretoria, 0001, South Africa
}

\begin{abstract}
Although fetomaternal disproportion is the major cause of dystocia in heifers, pelvis area (PA) is not recommended as a culling tool due to its relatively low importance and genetic correlation with calf birth weight (BWT), the most important factor associated with dystocia. The objective of this observational study of 484 limited bred yearling beef heifers was to compare the effects of different methods of adjustment of PA data for culling to select against dystocia. Multivariable analyses were used to determine predictors of PA, calf BWT, and dystocia. Hypothetical culling rates of 10 and $20 \%$ were then applied after ranking heifers by each of the following: unadjusted PA, PA adjusted to $365 \mathrm{~d}$ of age by subtracting $0.27 \mathrm{~cm}^{2}$ per day of age difference between each heifer's age and 365 d (APA), PA:prebreeding $\mathrm{BW}$ ratio (PA:BW), PA adjusted to the median $\mathrm{BW}$ of the group using the regression coefficient of PA on BW within age group (BWPA), and PA similarly adjusted to the median lean BW (LBWPA). Dam parity, sire, prebreeding age, prebreeding $\mathrm{BW}$, and prebreeding $\mathrm{BCS}$ were associated with PA whereas dam parity, sire, own
\end{abstract}

BWT, PA, AI bull, and calf gender were associated with calf BWT $(P<0.05)$. Dam parity, calf BWT, and either BWPA or LBWPA were the only independent predictors of dystocia $(P<0.05)$. Adjusting PA to BW or lean BW (LBW) improved the sensitivity and specificity to predict dystocia. After hypothetical culling by PA, retained heifers were heavier and had a higher calving rate and calves tended to be heavier at birth compared to culled heifers, but dystocia rates were not different. Culling by APA resulted in similar effects, except that dystocia rate tended to be lower in retained heifers. Culling by PA:BW resulted in lower dystocia rate in retained than in culled heifers, but retained heifers had lower prebreeding BW than culls. Culling by BWPA and LBWPA resulted in lower proportions with dystocia and a tendency towards higher calving rates in the retained heifers, without affecting the prebreeding BW or calf BWT. It is concluded that pelvimetry is a useful culling tool to aid in the management of dystocia in yearling heifers and that adjustment of PA to median BW or LBW within age group improves its accuracy and avoids the undesirable side effects.

Key words: beef cattle, culling, dystocia, heifer selection, pelvimetry, pelvis area

\section{INTRODUCTION}

Fetomaternal disproportion is the major cause of dystocia in heifers (Price and Wiltbank, 1978a) and attempts to prevent it have focused mainly on reducing the birth weight (BW) of the calf (Andersen et al., 1993) and ensur-

\footnotetext{
${ }^{1}$ The authors thank Roger and Lynette Wood of Johannesburg Water's Northern Farm for providing the animals, facilities, and farm data and Reinette van Reenen and Daleen Anderson for assistance with data capture.

${ }^{2}$ Corresponding author: dietmar.holm@up.ac.za

Received July 27, 2013.

Accepted February 27, 2014.
}

ing adequate breeding BW (King et al., 1993). Calf BWT and pelvis area (PA) contribute 33 and $12 \%$, respectively, towards dystocia in heifers (Wolverton et al., 1991). Breed effect on the incidence of dystocia is attributed to differences in the relative calf BWT, pelvis structure, and large variation in pelvis dimensions in some breeds (Price and Wiltbank, 1978a; Citek et al., 2011; Nogalski and Mordas, 2012). Heritability of calf BWT and PA are reported to be 0.44 and 0.46 , respectively, but heritable traits predict calving ease poorly in individuals (Andersen et al., 1993; Van Donkersgoed, 1997).

Cook et al. (1993) concluded that negative EPD for BWT in bulls was more effective in reducing dys- 
tocia rate and severity than culling heifers based on PA. Using bulls with low BWT or low BWT EPD to prevent dystocia has been challenged due to the correlation with lower growth rate and adult BW (Wolverton et al., 1991) and thus smaller PA. However, the benefit of increasing PA may in the same way be offset by increased calf BWT due to their genetic correlation (Andersen et al., 1993).

Adjusting PA to BW and to own BWT by ratios has been as disappointing as using raw PA for culling in heifers (Van Donkersgoed et al., 1993). Deutscher (1988) recommended culling of yearling heifers after adjustment of PA data to an age of $365 \mathrm{~d}$ by $0.27 \mathrm{~cm}^{2} / \mathrm{d}$ of age, and a similar method is currently used in beef cattle management software in South Africa (BeefPro; BenguelaSoft CC, Irene, South Africa).

The objective of this study was to compare the accuracy and effects of different methods of adjustment of PA data for culling to select against dystocia.

\section{MATERIALS AND METHODS}

This research was performed under protocol number V089/13, as approved by the Animal Ethics Committee of the University of Pretoria. This was an observational study of 484 Bovelder beef heifers born in either 2006 or 2007 (2006 and 2007 birth cohorts) that were followed from just before their first breeding season until they had calved for the first time. The farming system, breed, and location have been described previously (Paterson et al., 1980; Schoeman and Jordaan, 1998; Holm et al., 2008, 2009). Each animal in the study was uniquely identified.

Heifers were weighed within 1 mo preceding the mating start date (MSD; prebreeding BW), and internal vertical diameter of the pelvis (VD) and transverse diameter of the pelvis (TD) were measured within the $7 \mathrm{~d}$ preceding the MSD by transrectal placement of a caliper type pelvimeter (Rice pelvimeter; Lane Manufacturing, Denver, CO) between the cranial end of the symphysis pelvina and the dorsal wall of the pelvis and at the widest distance between the medial aspects of the corpora ossium iliorum, respectively (Wolverton et al., 1991; Cook et al., 1993; Van Donkersgoed, 1997). Body condition score was determined at the same time using a 9-point scale (Marston, 2005). For the purpose of regression models, BCS was categorized into 2 approximately equal sized categories $(<6$ and $\geq 6$ ) since relatively few animals had BCS $<5$ or BCS $>6$. Farm management and staff were blinded to PA and BCS data throughout the trial.

The MSD was October 15 of each year and breeding consisted of a 50-d AI period followed 5 to $7 \mathrm{~d}$ later by a 42-d clean-up bull breeding period. Pregnancy diagnoses were performed by transrectal palpation (Sheldon and Noakes, 2002) on April 1, 2008 (2006 cohort), and on March 3, 2009 (2007 cohort). Animals that were estimat- ed to have conceived during the bull breeding season and not during the AI season were sold as pregnant heifers.

Sire was defined as the sire of the heifer, and AI bull was the bull assigned to each heifer during the breeding season. All 7 and all 6 of the AI bulls allocated to the 2006 and 2007 birth cohorts, respectively, and 40 of the 45 bulls that sired the heifers in this trial originated from the same herd. Bulls with own BWT up to a maximum of $33 \mathrm{~kg}$ were allocated to nulliparous heifers and up to a maximum of $36 \mathrm{~kg}$ to primiparous cows, while controlling for inbreeding. In other data from this herd all bull calves born to 2 age cohorts of cows over 5 calving seasons $(n=393)$ had a median BWT of $36 \mathrm{~kg}$ (interquartile range $32-44 \mathrm{~kg}$ ). This strategy to reduce the incidence and severity of dystocia in heifers and primiparous cows had been in use for approximately $25 \mathrm{yr}$ in the herd before this study, and heifers had never been selected based on PA before or during this trial (R. J. Wood, Johannesburg Water, 2007, personal communication).

Farm data collected for each heifer included the following: dam parity, sire, birth date, BWT, occurrence of dystocia during her own birth, AI bull used, pregnancy diagnosis, calving date, calf BWT, calf gender, and dystocia score $(0=$ no assistance, $1=$ assistance required, and 2 = surgical intervention required).

Pelvis area was calculated as the product of the VD and TD. Lean BW (LBW) was calculated for each heifer by adjusting the BW to a lean BCS (score 4) using the formula

$$
\mathrm{LBW}=\mathrm{BW}-(\mathrm{BCS}-4) \times b_{1},
$$

in which $b_{1}$ is the regression coefficient of $\mathrm{BW}$ on $\mathrm{BCS}$ within own birth cohort. In the same way, PA adjusted to the median BW of the group using the regression coefficient of PA on BW within age group (BWPA) and PA similarly adjusted to the median lean BW (LBWPA) were calculated for each heifer by adjusting to the median BW and median LBW within birth cohort, respectively, using the formulas

$$
\mathrm{BWPA}=\mathrm{PA}-[\mathrm{BW}-\operatorname{Median}(\mathrm{BW})] \times b_{2} \text { and }
$$

$$
\mathrm{LBWPA}=\mathrm{PA}-[\mathrm{LBW}-\operatorname{Median}(\mathrm{LBW})] \times b_{3},
$$

in which $b_{2}$ is the regression coefficient of PA on BW and $b_{3}$ is the regression coefficient of PA on LBW, within own birth cohort.

Finally, hypothetical culling was applied at 10 and $20 \%$ culling rates after ranking all the heifers enrolled at the start on each of the following 5 criteria: 1) unadjusted PA, 2) PA adjusted to $365 \mathrm{~d}$ of age by subtracting $0.27 \mathrm{~cm}^{2}$ per day of age difference between each 
Table 1. Prebreeding and calving data by birth cohort

\begin{tabular}{|c|c|c|c|c|c|c|c|c|}
\hline \multirow[b]{3}{*}{ Variable } & \multicolumn{8}{|c|}{ Year of birth } \\
\hline & \multicolumn{4}{|c|}{$2006(n=225)$} & \multicolumn{4}{|c|}{$2007(n=259)$} \\
\hline & Mean & SD & Minimum & Maximum & Mean & SD & Minimum & Maximum \\
\hline Prebreeding BW, kg & $316^{\mathrm{a}}$ & 28 & 226 & 405 & $292^{\mathrm{b}}$ & 36 & 195 & 392 \\
\hline Prebreeding age, $\mathrm{d}$ & $407^{\mathrm{a}}$ & 21 & 336 & 459 & $401^{\mathrm{b}}$ & 31 & 311 & 449 \\
\hline Prebreeding BCS, 1-9 & $5.6^{\mathrm{a}}$ & 0.6 & 5 & 8 & $5.8^{\mathrm{b}}$ & 0.7 & 5 & 8 \\
\hline Prebreeding TD, ${ }^{1} \mathrm{~cm}$ & $11.1^{\mathrm{a}}$ & 0.8 & 9 & 13 & $11.0^{\mathrm{a}}$ & 0.9 & 8.5 & 13 \\
\hline Calf birth weight, $\mathrm{kg}$ & $29.8^{\mathrm{a}}$ & 4.1 & 17 & 40 & $28.4^{\mathrm{b}}$ & 4.5 & 18 & 41 \\
\hline No. that calved (\%) & \multicolumn{4}{|c|}{$136(60 \%)^{\mathrm{a}}$} & \multicolumn{4}{|c|}{$128(49 \%)^{b}$} \\
\hline No. with dystocia (\%) & \multicolumn{4}{|c|}{$46(34 \%)^{\mathrm{a}}$} & \multicolumn{4}{|c|}{$42(33 \%)^{b}$} \\
\hline
\end{tabular}

a,b Means and proportions with different superscripts between years of birth differ significantly $(P<0.05)$.

${ }^{1} \mathrm{TD}=$ transverse diameter of the pelvis.

${ }^{2} \mathrm{VD}=$ vertical diameter of the pelvis.

${ }^{3} \mathrm{PA}=$ pelvis area

heifer's age and 365 d (APA; Siemens et al., 1991; Price and Wiltbank, 1978b), 3) PA:prebreeding BW ratio (PA:BW; Van Donkersgoed et al., 1993), 4) BWPA, and 5) LBWPA. Effects and side effects of hypothetical culling after the different ranking procedures were determined by comparing prebreeding BW, calving and dystocia rates, unassisted calving rate, and calf BWT between those heifers that were culled and those that were retained, for each level of culling. Sensitivity (Sen) and specificity (Sp) for the correct prediction of dystocia were also determined for each ranking procedure and for each culling level as follows:

Sen $=$ number of culled heifers with dystocia/total number of dystocia cases and

$\mathrm{Sp}=$ number of retained heifers with unassisted births/total number of unassisted births.

\section{Analytical Procedures}

Data of the 2 birth cohorts were pooled, and subsequently analyzed using NCSS 2007 (NCSS, Kaysville, UT) and STATA 11.1 (StataCorp, College Station, TX). Proportions were compared using the Fisher's exact test in the case of independent proportions, and means were compared using ANOVA with the Tukey-Kramer multiple comparison test.

Multiple regression models of PA, VD, TD, and calf BWT and logistic regression models of dystocia were constructed by first adding all available predictors as covariates. Initial covariates in the models of PA, VD, and TD were parity of the dam $(1,2$, and $\geq 3)$, BWT of the heifer, prebreeding $\mathrm{BW}$, and $\mathrm{BCS}$ and age at prebreeding examination. Initial covariates in the model of calf BWT were the same as for the model of PA except that age at calving replaced prebreeding age and calf gender and PA were also included as covariates. Initial covariates in the logistic regression model of dystocia were the same as for the model of calf BWT except that the heifer's own dystocia score and calf BWT were also included. Year of birth was forced into all models. This was followed by a stepwise reduction of covariates based on the highest Wald $P$-values until only covariates that were independently associated with the outcome $(P<0.05)$ remained. Following this, variables were added back into the model one by one and retained if significant. Variables were considered to be confounders if adding them to the models changed the coefficients of other covariates by more than $15 \%$, in which case they were retained in the models. Pelvis area (the main variable of interest) was forced into the model and sire and AI bull were included as random effects and retained if significant $(P<0.05)$. The resultant mixed models therefore estimated sire and AI bull variances and adjusted all other effects in the model for these random effects.

Sensitivity and $\mathrm{Sp}$ of different culling procedures for dystocia were compared using conditional logistic regression. Areas under the receiver operating characteristic (ROC) curves for prediction of dystocia by the 5 different culling procedures were compared using the algorithm of DeLong et al. (1988).

\section{RESULTS}

The heifers born in 2006 were older and heavier at the time of examination and had greater calf BWT and VD and larger PA than those born in 2007 (Table 1). The calving rate was also higher in the group born in 2006, but the dystocia rate was the same in the $2 \mathrm{yr}$ of birth. 
Table 2. Regression coefficients used to calculate lean BW, BW adjusted pelvis area, and lean BW adjusted pelvis area

\begin{tabular}{|c|c|c|c|c|c|}
\hline Dependent variable & Independent variable & Used in calculation of & Age cohort & Regression coefficient $(\beta)$ & $R^{2}$ \\
\hline \multirow[t]{2}{*}{ Birth weight, kg } & Body condition score, $1-9$ & Lean BW (LBW), kg & 2006 & $9.4 \mathrm{~kg} / \mathrm{BCS}$ & 0.05 \\
\hline & & & 2007 & $19.8 \mathrm{~kg} / \mathrm{BCS}$ & 0.18 \\
\hline \multirow[t]{2}{*}{ Pelvis area $(\mathrm{PA}), \mathrm{cm}^{2}$} & $\mathrm{BW}, \mathrm{kg}$ & $\mathrm{BW}$ adjusted $\mathrm{PA}, \mathrm{cm}^{2}$ & 2006 & $0.23 \mathrm{~cm}^{2} / \mathrm{kg}$ & 0.17 \\
\hline & & & 2007 & $0.34 \mathrm{~cm}^{2} / \mathrm{kg}$ & 0.45 \\
\hline \multirow[t]{2}{*}{$\mathrm{PA}, \mathrm{cm}^{2}$} & LBW, $\mathrm{kg}$ & LBW adjusted PA, $\mathrm{cm}^{2}$ & 2006 & $0.24 \mathrm{~cm}^{2} / \mathrm{kg}$ & 0.18 \\
\hline & & & 2007 & $0.36 \mathrm{~cm}^{2} / \mathrm{kg}$ & 0.42 \\
\hline
\end{tabular}

Only $4(2.9 \%)$ and $2(1.5 \%)$ dystocia cases requiring surgical intervention (score 2) were reported in heifers born in 2006 and 2007, respectively; therefore, dystocia scores 1 and 2 were combined in further analyses.

Prebreeding BW was correlated with prebreeding age, VD, and TD (Pearson $r=0.44, r=0.50$, and $r=$ 0.46 , respectively; $P<0.05)$. Prebreeding age was correlated with VD and TD and the latter 2 were also correlated ( $r=0.28, r=0.44$, and $r=0.33$, respectively; $P<$ 0.05). Although correlations followed the same general trends within years of birth, coefficients were higher in the 2007 than in the 2006 cohort. Regression coefficients used to calculate BWPA, LBW, and LBWPA are presented in Table 2.

In the multiple regression model of PA (Table 3), both prebreeding age and BW were positively associated with PA, low prebreeding BCS was associated with larger PA (when adjusted for BW), and the random effect of sire was significant. The multiple regression model of calf BWT (Table 4) shows that the parity of the heifer's dam (1 vs. 3 or more), the heifer's own BWT, the prebreeding PA of the heifer, the age of the heifer at calving, and the gender of the calf were all associated with calf BWT $(P<0.05$; adjusted for year of birth) and the random effects of sire and AI bull were significant.

For every $1 \mathrm{~kg}$ increase in calf BWT the odds of dystocia increased by $37 \%$ after adjusting for year of birth, dam parity, and PA (Table 5). Also, for every $1 \mathrm{~cm}^{2}$ increase in PA, the odds of dystocia tended to decrease by $2 \%$ after adjusting for calf BWT, year of birth, and dam

Table 3. Multiple regression model of factors associated with pelvis area $\left(\mathrm{cm}^{2}\right)$

\begin{tabular}{|c|c|c|c|c|c|}
\hline \multirow{2}{*}{$\begin{array}{l}\text { Variable } \\
\text { Year of birth (2006 vs. 2007) }\end{array}$} & \multirow{2}{*}{$\frac{\text { Coefficient }}{-1.72}$} & \multirow{2}{*}{$\frac{\mathrm{SE}}{1.53}$} & \multicolumn{2}{|c|}{$95 \% \mathrm{CI}^{1}$} & \multirow{2}{*}{$\frac{P \text {-value }}{0.26}$} \\
\hline & & & -4.72 & 1.29 & \\
\hline Dam parity (1 vs. $\geq 3$ ) & -1.60 & 2.34 & -6.19 & 3.00 & 0.50 \\
\hline Dam parity ( 2 vs. $\geq 3$ ) & -4.17 & 2.05 & -8.19 & -0.14 & 0.04 \\
\hline Prebreeding age, $\mathrm{d}$ & 0.14 & 0.04 & 0.05 & 0.22 & $<0.01$ \\
\hline Prebreeding BW, kg & 0.25 & 0.03 & 0.20 & 0.30 & $<0.01$ \\
\hline Prebreeding BCS ( $\geq 6$ vs. $<6$ ) & -3.44 & 1.38 & -6.15 & -0.73 & 0.01 \\
\hline \multicolumn{6}{|c|}{ Random effects, variance (SE); 95\% CI } \\
\hline Sire & \multicolumn{5}{|c|}{$8.03(5.12) ; 2.30,28.04$} \\
\hline Residual & \multicolumn{5}{|c|}{$174.7(12.3) ; 152.2,200.6$} \\
\hline
\end{tabular}

${ }^{1} \mathrm{CI}=$ confidence iterval. parity $(P=0.08$; Table 5$)$. In this model the random effects of sire or AI bull were not significant.

Neither the heifer's own BWT nor the occurrence of dystocia during her own birth was associated with dystocia at her first calving, even after adjusting for any of the other covariates. Heifers born from second parity cows were 2.63 times more likely to develop dystocia during their first calving compared to those born from first parity heifers $(P=0.02)$ and tended to be more at risk compared to heifers born from third and greater parity cows (odds ratio $=1.86 ; P=0.08$ ) after adjusting for year of birth. Heifers born from second parity cows in 2007 were significantly lighter prebreeding than those born from first and third and higher parity cows in the same year (mean $\pm \mathrm{SD} 278 \pm 28 \mathrm{~kg}$ vs. $290 \pm 26 \mathrm{~kg}, P=$ 0.02 , and $298 \pm 40 \mathrm{~kg}, P<0.01$, respectively).

The 5 different ranking procedures of PA data for prediction of dystocia resulted in significantly different Sen for dystocia $(P=0.02$ and $P=0.04$ at 10 and $20 \%$ culling, respectively). The Sen of PA for dystocia was lower than that of all the adjusted PA variables at $10 \%$ culling and also lower than BWPA and LBWPA at 20\% culling rate (Table 6). The $\mathrm{Sp}$ of the different ranking procedures only differed at the $10 \%$ culling rate $(P=$ $0.01)$, when the Sp of PA and BWPA for dystocia was higher than that of APA (Table 6). Overall, LBWPA predicted dystocia better than PA and APA at the 20\% culling rate $(P<0.05$ using ROC analysis; Table 6$)$.

Table 4. Multiple regression model of factors associated with calf birth weight $(\mathrm{kg})$

\begin{tabular}{lccrrr}
\hline \hline Variable & Coefficient & SE & \multicolumn{2}{c}{$95 \% \mathrm{CI}^{1}$} & $P$-value \\
\hline Year of birth (2006 vs. 2007) & 1.18 & 0.88 & -0.53 & 2.90 & 0.18 \\
Dam parity (1 vs. $\geq 3$ ) & 1.90 & 0.93 & 0.07 & 3.72 & 0.04 \\
Dam parity (2 vs. $\geq 3)$ & 1.32 & 0.85 & -0.34 & 2.97 & 0.12 \\
Own birth weight, kg & 0.21 & 0.06 & 0.09 & 0.32 & $<0.01$ \\
Age at calving, d & 0.02 & 0.01 & 0.00 & 0.05 & 0.05 \\
Pelvis area, cm ${ }^{2}$ & 0.05 & 0.02 & 0.01 & 0.08 & $<0.01$ \\
Male vs. female calf & 2.58 & 0.49 & 1.63 & 3.55 & $<0.01$ \\
Random effects, variance (SE); 95\% CI & & & & \\
Sire & \multicolumn{5}{c}{$1.78(1.10) ; 0.53,5.98$} \\
AI bull & $13.03(1.34) ; 10.66,15.95$ \\
Residual & \multicolumn{5}{c}{$0.20,5.46$} \\
\hline
\end{tabular}

${ }^{1} \mathrm{CI}=$ confidence iterval. 
Table 5. Association between the outcome of an unassisted versus assisted birth for factors included in the logistic regression model

\begin{tabular}{lccccc}
\hline \hline Variable & $\mathrm{OR}^{1}$ & $\mathrm{SE}$ & \multicolumn{2}{c}{$95 \% \mathrm{CI}^{2}$} & $P$-value \\
\hline Year of birth (2006 vs. 2007) & 0.61 & 0.19 & 0.32 & 1.14 & 0.12 \\
Dam parity (1 vs. $\geq 3)$ & 0.45 & 0.18 & 0.21 & 0.97 & 0.04 \\
Dam parity (2 vs. $\geq 3)$ & 2.15 & 0.89 & 0.96 & 4.82 & 0.06 \\
Pelvis area, cm ${ }^{2}$ & 0.98 & 0.01 & 0.96 & 1.00 & 0.08 \\
Calf birth weight, $\mathrm{kg}$ & 1.37 & 0.06 & 1.25 & 1.51 & $<0.01$ \\
\hline
\end{tabular}

${ }^{1} \mathrm{OR}=$ odds ratio.

${ }^{2} \mathrm{CI}=$ confidence iterval.

After hypothetical culling by PA, heifers that were retained were heavier and had a higher calving rate and calves tended to be heavier at birth compared to the culled heifers $(P=0.08)$, but the dystocia rate was not different (Table 7). Culling by APA also resulted in higher mean prebreeding BW of retained heifers (Table 7) and a tendency of higher mean calf BWT at $10 \%$ culling ( 29.3 vs. $27.8 \mathrm{~kg} ; P=0.10)$. Culling by APA further resulted in a tendency towards a lower dystocia rate (Table 7). Culling by PA:BW resulted in a significantly lower dystocia rate in retained than in culled heifers, but retained heifers had lower prebreeding BW than culls (Table 7). No differences in calving rate or calf BWT occurred after culling by PA:BW.

Culling by BWPA or LBWPA resulted in a lower proportion with dystocia and a tendency towards a higher proportion of calves born in the retained heifers compared to culls, without affecting the prebreeding BW or calf BWT (Table 7).

\section{DISCUSSION}

In this study the effects of different ranking procedures of PA data used to hypothetically cull heifers before breeding were compared to determine the accuracy of each procedure to select against dystocia as well as the side effects of culling due to associations with fertility, BW, and calf BWT. The study further investigated whether sire, own BWT of a heifer, or the parity of her dam were associated with dystocia.

The differences in numbers, BW, age, VD, and calving rate between the $2 \mathrm{yr}$ of birth most likely occurred as a result of stricter prebreeding culling based on BW in heifers born in 2006, which also accounted for the lower variability and weaker correlations in data of heifers born in 2006 (Tables 1 and 2). Despite the differences between the 2 birth cohorts, dystocia rates were similar. This, combined with a previous finding by Micke et al. (2010) that the association between prebreeding PA and dystocia was not altered by differing levels of management after the application of pelvimetry, supports our assumption that the pooling of data in this study was valid.

Dystocia requiring surgical intervention had a low incidence in this study, supporting the binary classification used (Johanson and Berger, 2003; Zaborski et al., 2009; Citek et al., 2011). Pelvis area measured by the Rice pelvimeter is accurate when compared to carcass measurements (Kolkman et al., 2009) and moderately to substantially repeatable between and within veterinarians (Van Donkersgoed et al., 1993). Breed differences in pelvis conformation (Citek et al., 2011) support the use of PA rather than TD or VD for application of pelvic measures across breeds.

Based on the results of the multiple regression model of PA presented in Table 3, it is evident that BW and age have both joint and independent associations with PA. In other words, if a number of heifers of the same BW are compared, then the older of those will have larger PA, and similarly if a number of heifers of the same age are compared, then the heavier of those will have larger PA. However, adjusting PA to determine the relative size of the pelvis can be done either by adjusting to BW or to age but not both simultaneously, due to the strong correlation between BW and age (Deutscher, 1988). From the

Table 6. Accuracy of hypothetical culling after different pelvis area ranking procedures for prediction of dystocia

\begin{tabular}{|c|c|c|c|c|c|c|}
\hline \multirow[b]{3}{*}{ Ranking procedure } & \multicolumn{6}{|c|}{ Culling rate } \\
\hline & \multicolumn{3}{|c|}{$10 \%$} & \multicolumn{3}{|c|}{$20 \%$} \\
\hline & $\operatorname{Sen}^{1}$ & $\mathrm{Sp}^{2}$ & ${\mathrm{ROC}-\mathrm{AUC}^{3}}^{2}$ & $\operatorname{Sen}^{1}$ & $\mathrm{Sp}^{2}$ & $\mathrm{ROC}_{-\mathrm{AUC}^{3}}$ \\
\hline Pelvis area unadjusted & $0.05^{\mathrm{a}}$ & $0.97^{\mathrm{a}}$ & $0.51^{\mathrm{a}}$ & $0.17^{\mathrm{a}}$ & $0.87^{\mathrm{a}}$ & $0.53^{\mathrm{a}}$ \\
\hline Pelvis area adjusted to $365 \mathrm{~d}$ age using a fixed correction factor of $0.27 \mathrm{~cm}^{2} / \mathrm{d}$ of age & $0.11^{\mathrm{b}}$ & $0.92^{\mathrm{b}}$ & $0.52^{\mathrm{a}}$ & $0.24^{\mathrm{a}, \mathrm{b}}$ & $0.86^{\mathrm{a}}$ & $0.56^{\mathrm{a}}$ \\
\hline Pelvis area:BW ratio & $0.14^{\mathrm{b}}$ & $0.94^{\mathrm{b}, \mathrm{c}}$ & $0.54^{\mathrm{a}}$ & $0.27^{\mathrm{b}}$ & $0.85^{\mathrm{a}}$ & $0.56^{\mathrm{a}, \mathrm{b}}$ \\
\hline Pelvis area adjusted to BW by the linear regression coefficient & $0.15^{\mathrm{b}}$ & $0.97^{\mathrm{a}, \mathrm{c}}$ & $0.56^{\mathrm{a}}$ & $0.26^{\mathrm{a}, \mathrm{b}}$ & $0.88^{\mathrm{a}}$ & $0.55^{\mathrm{a}, \mathrm{b}}$ \\
\hline Pelvis area adjusted to lean BW by the linear regression coefficient & $0.13^{\mathrm{b}}$ & $0.95^{\mathrm{a}, \mathrm{b}, \mathrm{c}}$ & $0.54^{\mathrm{a}}$ & $0.30^{\mathrm{b}}$ & $0.89^{\mathrm{a}}$ & $0.59^{\mathrm{b}}$ \\
\hline Model $P$-value & 0.022 & 0.014 & 0.086 & 0.037 & 0.427 & 0.021 \\
\hline
\end{tabular}


Table 7. The effects that culling the lowest $20 \%$ of heifers would have on the retained heifers relative to those that were culled by using various ranking procedures

\begin{tabular}{|c|c|c|c|c|c|c|c|}
\hline $\begin{array}{l}\text { Ranking } \\
\text { procedure }\end{array}$ & $\begin{array}{l}\text { Cohort } \\
\text { of heifers }\end{array}$ & $n$ & $\begin{array}{c}\text { Mean } \\
\text { prebreeding BW, } \\
\mathrm{kg}\end{array}$ & $\begin{array}{l}\text { Calves born } \\
\text { (proportion } \\
\text { of total bred) }\end{array}$ & $\begin{array}{c}\text { Dystocia } \\
\text { (proportion } \\
\text { of calves born) }\end{array}$ & $\begin{array}{l}\text { Unassisted births } \\
\text { (proportion } \\
\text { of total bred) }\end{array}$ & $\begin{array}{c}\text { Mean calf } \\
\text { birth weight, } \\
\text { kg }\end{array}$ \\
\hline Pelvis area (PA) unadjusted & Retained & 387 & $309.8^{* *}$ & $226(59 \%)^{* *}$ & $73(32 \%)$ & $153(40 \%)^{* *}$ & $29.3 *$ \\
\hline \multirow{2}{*}{$\begin{array}{l}\text { PA adjusted to } 365 \mathrm{~d} \text { of age using a } \\
\text { correction factor of } 0.27 \mathrm{~cm}^{2} / \mathrm{d}\end{array}$} & Retained & 389 & $308.0^{* *}$ & $219(56 \%)$ & $67(31 \%)^{*}$ & $152(39 \%)^{* *}$ & 29.2 \\
\hline & Culled & 95 & $284.3^{* *}$ & $45(47 \%)$ & $21(47 \%)^{*}$ & $24(25 \%)^{* *}$ & 28.8 \\
\hline \multirow{2}{*}{$\begin{array}{l}\text { PA adjusted to BW by the regression } \\
\text { coefficient of PA on BW }\end{array}$} & Retained & 387 & 303.4 & $219(57 \%)^{*}$ & $65(30 \%)^{* *}$ & $154(40 \%)^{* *}$ & 29.3 \\
\hline & Culled & 97 & 303.6 & $45(46 \%)^{*}$ & $23(51 \%)^{* *}$ & $22(23 \%)^{* *}$ & 28.7 \\
\hline \multirow{2}{*}{$\begin{array}{l}\text { PA adjusted to lean BW by the } \\
\text { regression coefficient of PA on lean BW }\end{array}$} & Retained & 385 & 303.9 & $219(57 \%)^{*}$ & $62(28 \%)^{* *}$ & $157(41 \%)^{* *}$ & 29.0 \\
\hline & Culled & 99 & 301.2 & $45(45 \%)^{*}$ & $26(58 \%)^{* *}$ & $19(19 \%)^{* *}$ & 29.5 \\
\hline
\end{tabular}

**Values in columns within ranking procedure with different superscripts differ significantly $(P<0.05)$.

*Values in columns within ranking procedure tend to differ $(P<0.10)$.

results presented in Table 3 adjusting for BW appears most appropriate due to the stronger association with PA.

Similar to previous studies, calf BWT in our data was the single most important determinant of dystocia, whereas PA tended to be associated with dystocia only when adjusted for calf BWT (Van Donkersgoed, 1997; Cook et al., 1993; Price and Wiltbank, 1978b). The lack of statistical significance in the association of PA, APA, or PA:BW with dystocia could have been a result of inadequate sample size; however, BWPA and LBWPA were both significantly associated with dystocia after adjusting for calf BWT, further indicating that the adjustment by BW or LBW was the most appropriate.

The findings of the present study occurred in heifers measured as yearlings, with a dystocia rate of $33 \%$, whereas in the study reported by Van Donkersgoed et al. (1993) the dystocia rate was 18 or $19 \%$ in heifers that were a year older than the heifers in our study. The reason for the difference in Sen using PA or PA:BW reported in this study and that of Van Donkersgoed et al. (1993) may be that the relative threshold determining test positive (culling) status is changed if a similar culling rate is maintained while the prevalence changes (Dohoo et al., 2003). For this reason a culling rate that suits the population tested should be applied: a lower culling rate is indicated in herds with a low risk of dystocia if high $\mathrm{Sp}$ is desired.

The consistently high $\mathrm{Sp}$ in both studies indicates that the test may be generally valid as a culling tool, where the incorrect culling of many "disease negative" animals is potentially economically more damaging than keeping "disease positive" animals in the herd (Chenoweth, 2005). If BWPA was used to cull $10 \%$ heifers in the current study, $85 \%$ of dystocia cases would not have been predicted by the test, but only $3 \%$ of heifers that calved without assistance ("disease negative") were incorrectly culled by the test. For a test that is applied as a culling tool, this high Sp makes it useful, as long as it is assumed that the Sen is poor and that many unpredicted dystocia cases will still occur. This was not considered in the interpretation by Van Donkersgoed et al. (1993).

When PA was used as culling procedure, it resulted in an increased proportion of unassisted births in retained heifers, but this was paradoxically as a result of significant differences in calving rate and not dystocia rate. It also tended to increased calf BWT at a 20\% culling rate in retained heifers relative to culls due to its correlation with frame size, which would likely offset the benefit of larger PA (Andersen et al., 1993; Laster, 1974). Price and Wiltbank (1978b) showed that Angus heifers had lower BW and calf BWT, smaller PA, and less dystocia than their Charolais counterparts, and this can possibly be explained by the fact that the BWT of the calf as proportion of the dam's BW increases with increasing BW of the cow (Holland and Odde, 1992). Because PA is associated with calving rate, it may also be associated with age at calving, which may result in a confounding effect of PA on dystocia (Andersen et al., 1993; Zaborski et al., 2009). However, in this data age at calving was not associated with dystocia (Table 5). Although culling based on PA was not effective in decreasing the dystocia rate in our data, it is currently widely used, and the use of PA as culling tool may have a positive side effect of selecting for heifers with improved fertility.

The association of PA with fertility outcome is in agreement with findings that bulls with larger PA have shown improved libido (Singh et al., 2010) and that Jersey heifers with larger PA reached puberty at a lower BW and earlier age (Ramin et al., 1995) and needs further investigation. Further support for the relationship between PA and hormonal changes around puberty is the independent associations of age and BW with PA, 
being similar to what has been described for age at puberty (Yelich et al., 1995; Pence et al., 2007; Holm et al., 2009). Lesmeister (1976) demonstrated that TD development that was induced by progesterone and estradiol implantation in heifer calves precedes VD development. Other studies reported a biphasic growth pattern of the reproductive organs of heifers from birth to puberty (Desjardin and Hafs, 1969; Honaramooz et al., 2004), with the first phase before 6 mo of age under FSH stimulation and the second phase preceding puberty under LH stimulus (Day et al., 1987). It is possible that pelvis development follows a similar biphasic hormone stimulated pattern, and we hypothesize that inadequate $\mathrm{LH}$ levels due to lower BW resulted in smaller VD as well as more of the 2007 heifers not achieving estrus during the breeding season compared to those born in 2006.

Using a fixed correction factor of $0.27 \mathrm{~cm}^{2} / \mathrm{d}$ of age to adjust PA to $365 \mathrm{~d}$ increased the Sen but decreased the Sp of culling, without reducing the negative side effects such as the birth of heavier calves and selection of heavier heifers, compared to using PA (Tables 6 and 7). There was a much weaker association with calving rate than when PA was used, and as a result the proportion of unassisted births only increased significantly at the $20 \%$ culling rate. The reason may be that the correction factor was inappropriate for the study population or that adjusting for age did not provide a measure of PA relative to frame size. Larger framed heifers likely to give birth to heavier calves but that are younger at the time of examination will be favored by this procedure. Taylor et al. (2008) showed that large framed heifers reproduce less efficiently over the long term than their small- and medium-framed counterparts in extensive systems of Southern Africa, making selection based on unadjusted PA potentially inappropriate.

Culling by PA:BW resulted in a significant decrease in dystocia rate in the retained heifers compared to the culls but there was no effect on calving rate, probably due to the fact that this procedure resulted in retained heifers being lighter than culls and therefore less likely to become pregnant during the restricted breeding season. These findings are similar to those previously reported using this method (Basarab et al., 1993; Van Donkersgoed et al., 1993), and it is likely that the relative numerical value of BW compared to PA overemphasizes the former in the ranking procedure, resulting in heavier heifers being culled. Although this procedure resulted in the best Sen at $5 \%$ culling rate in our data, it is not recommended due to its negative association with BW.

Adjusting PA to the median BW by the regression coefficient of PA on BW significantly increased Sen at the $10 \%$ culling rate (Table 6 ) and appeared to cull heifers more efficiently for dystocia than for fertility (Table 7). The BW of retained and culled heifers as well as the BWT of their calves was similar, indicating that this ad- justment of PA data effectively avoided accidental culling based on frame size.

The negative association between BCS and PA was only significant when adjusted for BW; in other words, for any given BW, PA was larger in heifers with lower BCS, reasoned to be due to a larger frame size. This assumption formed the basis of our adjustment of LBWPA. Lean BW was first determined in an attempt to represent the frame size of the heifer, which was then used to adjust PA to have a measure of PA relative to frame size. Although the negative association of PA with BCS was similar for $\mathrm{TD}$, it was not the case for VD, and in a study of Belgian Blue cows between 2 and $10 \mathrm{y}$ of age that were measured before slaughter and compared with carcass measurements, this association was not evident (Kolkman et al., 2009). Another possible explanation for the negative association between BCS and TD may be that higher levels of endogenous steroid hormones may lead to lower BCS and increased TD, particularly at a young age (Lesmeister, 1976). In the current study of the effects of different ranking procedures of PA as culling tool for dystocia, BWPA and LBWPA performed similarly, except that LBWPA appeared to be more accurate at higher culling rates while BWPA appeared more accurate at lower culling rates. Further research is needed to clarify the effect of BCS on PA, to validate either BWPA or LBWPA.

There was no evidence from the present data that a heifer's own BWT was negatively associated with the occurrence of dystocia at the time of her first calving. In a herd such as this with very uniform animals (Schoeman and Jordaan, 1998) and where low BWT bulls had been used to control the incidence and severity of dystocia for $>25 \mathrm{yr}$ (R. J. Wood, Johannesburg Water, 2007, personal communication), such an association would most likely have been demonstrable if it existed. In fact, in the present study heifers born from second parity cows were more at risk of developing dystocia, despite the fact that heavier BWT bulls sired them compared to daughters of first parity cows. The reason for this increased risk was not related to BWT but was most likely related to the fact that heifers born from second parity cows in 2007 were lighter prebreeding than those born from first and third and higher parity cows in the same year.

We recommend that current practices using PA, APA, or PA:BW ratios to rank heifers for culling should be revised due to their associations with frame size and calf BWT and that ranking heifers based on their BW adjusted PA or lean BW adjusted PA should be considered. Since our data failed to demonstrate an association between own BWT and dystocia, it is further recommended that the use of bulls with low BWT or low BWT EPD and adequate nutrition of developing heifers can be combined with culling by BW adjusted PA in sustainable management programs for dystocia in beef heifers. 


\section{Conclusions}

It is concluded that ranking by PA is a valid culling tool for yearling heifers, with a consistently high Sp for dystocia. Adjustment of PA data to median BW or LBW within age group improves its accuracy and avoids undesirable side effects.

\section{LITERATURE CITED}

Andersen, K. J., J. S. Brinks, D. G. LeFever, and K. G. Odde. 1993. The factors associated with dystocia in cattle. Vet. Med. 88:764-776.

Basarab, J. A., L. M. Rutter, and P. A. Day. 1993. The efficacy of predicting dystocia in yearling beef heifers: I: Using ratios of pelvic area to birth weight or pelvic area to heifer weight. J. Anim. Sci. 71:1359-1371.

Chenoweth, P. J. 2005. Herd health management. In: P. J. Chenoweth and M. W. Sanderson, editors, Beef practice: Cow-calf production medicine. Blackwell Publishing, Ames, IA. p. 65-80.

Citek, J., E. Hradecka, V. Rehout, and L. Hanusova. 2011. Obstetrical problems and stillbirth in beef cattle. Anim. Sci. Pap. Rep. 29:109-118.

Cook, B. R., M. W. Tess, and D. D. Kress. 1993. Effects of selection strategies using heifer pelvic area and sire birth weight expected progeny difference on dystocia in first-calf heifers. J. Anim. Sci. 71:602-607.

Day, M. L., K. Imakawa, P. L. Wolfe, R. J. Kittok, and J. E. Kinder. 1987. Endocrine mechanisms of puberty in heifers. Role of hypothalamopituitary estradiol receptors in the negative feedback of estradiol on luteinizing hormone secretion. Biol. Reprod. 37:1054-1065.

DeLong, E. R., D. M. DeLong, and D. L. Clarke-Pearson. 1988. Comparing the areas under two or more correlated receiver operating curves: A nonparametric approach. Biometrics 44:837-845.

Desjardin, C., and H. D. Hafs. 1969. Maturation of bovine female genitalia from birth through puberty. J. Anim. Sci. 28:502-507.

Deutscher, G. H. 1988. Pelvis measurements: Key to reducing incidence of bovine dystocia. Norden News 63(2):18-25.

Dohoo, I., W. Martin, and H. Stryhn. 2003. Screening and diagnostic tests. In: I. Dohoo, W. Martin, and H. Stryhn, editors, Veterinary epidemiologic research. AVC Inc., Charlottetown, Canada. p. 85-120.

Holland, M. D., and K. G. Odde. 1992. Factors affecting calf birth weight: A review. Theriogenology 38:769-798.

Holm, D. E., P. N. Thompson, and P. C. Irons. 2008. The economic effects of an estrus synchronization protocol using prostaglandin in beef heifers. Theriogenology 70:1507-1515.

Holm, D. E., P. N. Thompson, and P. C. Irons. 2009. The value of reproductive tract scoring as a predictor of fertility and production outcomes in beef heifers. J. Anim. Sci. 87:1934-1940.

Honaramooz, A., J. Aravindakshan, R. K. Chandolia, A. P. Beard, P. M. Bartlewski, R. A. Pierson, and N. C. Rawlings. 2004. Ultrasonographic evaluation of the pre-pubertal development of the reproductive tract in beef heifers. Anim. Reprod. Sci. 80:15-29.

Johanson, J. M., and P. J. Berger. 2003. Birth weight as a predictor of calving ease and perinatal mortality in Holstein cattle. J. Dairy Sci. 86:3745-3755.

King, B. D., R. D. H. Cohen, S. McCormac, and C. L. Guenther. 1993. Maternal factors and the prediction of dystocia in beef heifers. Can. J. Anim. Sci. 73:431-435.

Kolkman, I., G. Hoflack, S. Aerts, R. D. Murray, G. Opsomer, and D. Lips. 2009. Evaluation of the Rice pelvimeter for measuring pelvic area in double muscled Belgian Blue cows. Livest. Sci. 121:259-266.
Laster, D. 1974. Factors affecting pelvic size and dystocia in beef cattle. J. Anim. Sci. 38:496-503.

Lesmeister, J. L. 1976. Hormonal effects on pelvic development and calving difficulty in beef cows (abstract). Diss. Abstr. Int. 36(8):3693.

Marston, T. T. 2005. Beef cowherd nutrition and management. In: P. J. Chenoweth and M. W. Sanderson, editors, Beef practice: Cow-calf production medicine. Blackwell Publishing., Ames, IA. p. 89-108.

Micke, G. C., T. M. Sullivan, P. J. Rolls, B. Hasell, P. M. Greer, S. T. Norman, and V. E. A. Perry. 2010. Dystocia in 3-year-old beef heifers; Relationship to maternal nutrient intake during earlyand mid-gestation, pelvic area and hormonal indicators of placental function. Anim. Reprod. Sci. 118:163-170.

Nogalski, Z., and W. Mordas. 2012. Pelvic parameters in HolsteinFriesian and Jersey heifers in relation to their calving. Pak. Vet. J. 32:507-510.

Paterson, A. G., H. A. W. Venter, and G. O. Harwin. 1980. Preweaning growth of British, Bos indicus, Charolais and dual purpose type cattle under intensive pasture conditions. S. Afr. J. Anim. Sci. 10:125-134.

Pence, M., D. Ensley, R. Berghaus, J. Rossi, T. Wilson, and P. T. Cannon. 2007. Improving reproductive efficiency through the use of reproductive tract scoring in a group of beef replacement heifers. Bov. Pract. 41:35-40.

Price, T. D., and J. N. Wiltbank. 1978a. Dystocia in cattle. A review and implications. Theriogenology 9(3):195-219.

Price, T. D., and J. N. Wiltbank. 1978b. Predicting dystocia in heifers. Theriogenology 9:221-249.

Ramin, A. G., R. C. W. Daniel, D. C. Fenwick, and R. G. Verrall. 1995. Pelvic parameters, growth rate, puberty, and their interrelationships in young dairy heifers. Reprod. Domest. Anim. 30:117-123.

Schoeman, S. J., and G. G. Jordaan. 1998. Animal x testing environment interaction on postweaning liveweight gains of young bulls. Aust. J. Agric. Res. 49:607-612.

Sheldon, M., and D. Noakes. 2002. Pregnancy diagnosis in cattle. In Practice 24:310-317.

Siemens, M. G., A. L. Siemens, R. J. Lipsey, G. H. Deutscher, and M. R. Ellersieck. 1991. Yearling adjustments for pelvic area of test station bulls. J. Anim. Sci. 69:2269-2272.

Singh, J., A. Kumar, and G. S. Dhaliwal. 2010. Pelvic area and scrotal circumference in relation to libido in breeding bulls. Indian Vet. J. 87:396-397.

Taylor, G. J., F. J. C. Swanepoel, E. C. Webb, and A. Stroebel. 2008. Effect of heifer frame size on their subsequent reproductive performance and preweaning performance of their calves. Aust. J. Exp. Agric. 48:945-949.

Van Donkersgoed, J. 1997. Pelvimetry. In: R. S. Youngquist, editor, Current therapy in large animal theriogenology W. B. Saunders, St. Louis, MO. p. 306-309.

Van Donkersgoed, J., C. S. Ribble, C. W. Booker, D. McCartney, and E. D. Janzen. 1993. The predictive value of pelvimetry in beef cattle. Can. J. Vet. Res. 57:170-175.

Wolverton, D. J., N. R. Perkins, and G. F. Hoffsis. 1991. Veterinary application of pelvimetry in beef cattle. Compend. Contin. Educ. Pract. Vet. 13:1315-1320.

Yelich, J. V., R. P. Wettemann, H. G. Dolezal, K. S. Lusby, D. K. Bishop, and L. J. Spicer. 1995. Effects of growth rate on carcass composition and lipid partitioning at puberty and growth hormone, insulin-like growth factor I, insulin, and metabolites before puberty in beef heifers. J. Anim. Sci. 73:2390-2405.

Zaborski, D., W. Grzesiak, I. Szatkowska, A. Dybys, M. Muszynska, and M. Jedrzejczak. 2009. Factors affecting dystocia in cattle. Reprod. Domest. Anim. 44:540-551. 